\title{
CUSTOMER RELATIONSHIP MANAGEMENT CAPTURES INTELLECTUAL CAPITAL FOR INCREASED COMPETITIVENESS
}

\author{
- INTELLECTUAL CAPITAL MANAGEMENT SERIES - \\ (Article 2 of 3)
}

\author{
CR van Zyl, Nedbank Limited
}

\begin{abstract}
Today, with regards to tangible assets, the corporate playing field has become more or less level with competing organisations producing very similar products and services. The key differentiator for an organisation's offerings now depends upon an organisation's ability to capture and leverage intellectual capital (IC), and especially customer IC. Customers are an invaluable source of two kinds of IC: transactional and innovative. An organisation must implement customer relationship management (CRM) initiatives in order to develop and maintain good relationships with customers and in so doing, be able to capture IC. This IC will enable an organisation to be more responsive to new and changing customer needs and preferences and to be better able to customize products and services according to more specific customer profiles: ultimately leading to increased market share, profitability and overall strategic competitiveness.
\end{abstract}

The purpose of this article is to determine how good customer relationships allow for the capture and subsequent leveraging of customer IC for increased competitiveness. In order to fulfill this purpose, the concept of CRM is explored as well as how CRM allows for the capture of both transactional and innovative capital. The strategic benefits of the application of customer IC are then explored, together with an exposition of the CRM implementation challenges facing those organisations that wish to implement a CRM program to capture and leverage customer IC for increased competitiveness.

This exploration involved an examination of contemporary literature, theories and business cases and subsequently revealed that CRM is a vital discipline/philosophy that must be implemented by any organisation wishing to achieve greater market efficiency and competitiveness. This competitiveness can only be achieved through the carefully managed unlocking, sharing and leveraging of both transactional and innovative customer intellectual capital.

Keywords and phrases: customer relationship management, competitive advantage, intellectual capital

\section{INTRODUCTION}

The implementation and adoption of supplier relationship management practices and principles is essential to any organisation wishing to capture and create intellectual capital and, thereby, increase the competitiveness and profitability of their supply chain. However, supplier relationships are only one part of relationship capital, with customer relationships representing another extremely valuable form of this capital.

Today, creating fool-proof high quality products is no longer as important as the ability to capture and conceptualise the ideas and thoughts behind the products. Customers are now increasingly more knowledgeable about what they wish to buy and, due to the Internet, have infinite amounts of market intelligence at their fingertips. Organisations are now continually challenged to identify 
and test strategic opportunities in order to plan for their future assets. Products are becoming totally customised to the point where there is no product and customers are the creators.

Therefore, core competency and competitive advantage are no longer found in the product or service itself, but in an organisation's design and marketing capabilities, as well as their ability to create good relationships with their customers and leverage the intellectual capital (IC) gleaned from these relationships to better customise products and respond to changing needs and preferences through the creation of new services and products faster and more continuously than competitors (Erb 2001: Internet)

The primary purpose of this article is to demonstrate that an organisation's customers are a very important source of valuable IC. Relationships with customers must be carefully managed through the application of customer relationship management (CRM) initiatives in order to capture their IC and leverage this capital to produce better products and services and to be more responsive to changing customer needs and preferences. This increased responsiveness leads to more satisfied and loyal customers, resulting in increased market share, profitability and an overall improved strategic competitive position for an organisation.

In order to satisfy the above-mentioned purpose, the article first explores the concept of CRM. In this section, it is demonstrated that customers are a source of two kinds of IC: the first is innovative capital that can be used for the development of new products and services; the second involves transactional capital, which is knowledge gained through customer interactions that can be used to develop better customer profiles for more customised product and service offerings. Both types of capital can be captured through effective CRM.

The article then explores the capturing of transactional capital, where the dimensions of CRM are investigated, with special attention being paid to the areas of web-enabled CRM, CRM call centres, and analytical CRM tools, as these have become important areas for the capture of customer data and the conversion of this into valuable IC.

Innovative capital is then explored and it is demonstrated that customers provide a valuable source of IC during new product development.

The strategic benefits of capturing and leveraging customer IC are then explored, followed by an exposition of the implementation challenges facing CRM initiatives that must be addressed by an organisation.

\section{CUSTOMER RELATIONSHIP MANAGEMENT DEFINED}

CRM stands for Customer Relationship Management and it can be broadly defined as a company's activities related to developing and retaining customers in an effort to develop longterm mutually beneficial links with them. It is a combination of internal business processes such as sales, marketing, and customer support with technology and data capturing techniques. CRM is all about building long-term business relationships with customers (AB Office Solutions 2003: Internet \& Du Plessis et al. 2002: 90)

The building of the above-mentioned business relationships requires co-operation, trust, commitment and the sharing of information, as well as the seamless integration of every area of business that touches the customer. This seamlessness is achieved through the integration of people, processes and technology, taking advantage of the revolutionary impact of the Internet 
and intranets. CRM initiatives also have a specific purpose to fulfill within the organisation and consist of various tasks (Du Plessis et al. 2002: 90).

CRM initiatives have two main purposes within the organisation. The first is to collect high quality customer information and create customer profiles. With access to detailed, up-to-date customer information, employees can handle customer's queries more effectively. Priority treatment can also be given to preferred customers, and further sales leads and product development related to customers' buying preferences can occur. Secondly, CRM initiatives should provide an interactive Web site or extranet to allow customers to access relevant information quickly and to serve themselves (Magic Software Enterprises 2000: Internet).

CRM initiatives also include various tasks, namely: collecting customer data in one place; making it widely available; identifying the best customers; discovering more like them; discerning their needs; and, eventually, turning prospects and first-time buyers into long-term loyal customers. CRM tasks allow an organisation to generate better sales leads, enable faster response to changing customer needs and to ensure that everyone in sales and marketing has the right information at the right time for every customer (Henricks 2000: Internet).

Customers are a source of IC for an organisation and CRM allows an organisation to manage and improve its relationships with their customers to capture and leverage this IC. CRM allows for the capture and leveraging of two types of IC: the first lies within the innovative capabilities of customers, e.g. customers are a valuable source of knowledge in the development of new products and services; the second lies within the knowledge gathered during transactions with customers e.g. call centre agents can discover new needs and preferences through unsatisfied customers calling their call centre.

\section{THE DIMENSIONS OF CRM}

The dimensions of CRM are explored as they pertain to the capturing of the second source of IC: transactional capital, which can be captured through routine customer transactions and customer complaints and requests.

The primary dimensions of CRM are: the three core areas of functionality (namely sales, marketing and customer service); a consistent, shared customer data repository; and analytical tools for mining the customer data to convert it into useful customer knowledge (Magic Software Enterprises 2000: Internet).

These dimensions include:

\section{- The Three Areas of Functionality}

CRM addresses the sales, marketing, and service activities of the organisation. These customer touch points must be managed to provide an enhanced customer relationship. All customer interactions must be managed through a common, integrated set of processes built on a sophisticated underlying technology that enables a consistent customer view.

The primary areas include:

- Service - the customer service (mainly provided through call centres) that an enterprise provides is key to its ability to create and retain satisfied, loyal 
customers. Customer IC must be available to staff to enable them to provide tailored and consistent service and to generate additional sales.

- Sales - the interaction of the sales force with a prospective customer, turning that prospect into a customer and then maintaining a loyal relationship, is a core business concern for enterprise success. The sales force is at the frontline of most customer relationships and must convey all their knowledge of customer needs and preferences (a source of IC for the firm) to the marketing, logistics and other relevant departments in order to ensure better tailoring of customer profiles and responsiveness to their emerging and changing needs.

- Marketing - marketing activities are evolving from traditional telemarketing to Web and e-mail campaigns. Information gathered from customers on the Web sites (e.g. their searches reveal their needs and preferences) must be converted into useful and valuable IC that can be shared and leveraged for increased competitiveness.

It is these primary areas where the customer makes contact with the organisation, either in a pre-sale, sale or post-sale situation, or as part of an ongoing relationship that requires service and information as well as the option of additional purchases. And it is within these areas that valuable IC pertaining to specific and changing customer needs and preferences can be captured and leveraged.

\section{- A Consistent, Shared Customer Repository}

Integrating customer interactions across the enterprise shifts organisations from departmentalised silos of customer contact to an environment where all customer interactions are co-ordinated and consistent. The customer repository must be at the centre of the sales, marketing and service efforts, as an organisation that functions with independent sources of information has duplicate, conflicting and out-of-date information that negatively influences the effectiveness of the entire enterprise. A central repository must be used to store the IC about customers so that it is made uniformly accessible to all. For example, a different call centre agent can access the same information on a specific customer's needs and preferences as a previous agent did. This ensures consistent interactions with customers; and results in consistent and satisfactory service delivery as well as satisfied customers.

\section{- Analytical Capabilities}

Real-time quantitative and qualitative analysis is an important dimension of CRM. Intelligent in-depth analysis requires consistent customer data as the starting point with all enterprise applications participating in the analytical environment. Added value is achieved by feeding the analysis results back to management and throughout the organisation. The enterprise decision-makers must then leverage this knowledge to make more informed and timely business decisions. 
The most important of the above-mentioned dimensions for the capturing and leveraging of IC include: web-enabled CRM; CRM call centres; and analytical tools and techniques for converting customer data into valuable IC. Each of these is explored in more detail below.

\section{Web-enabled CRM}

Many companies are developing and launching web sites where customers can search for information about products and services and their use, and even order online. The way customers search (what they look at), what specific customers buy and how often, and what questions are asked, serves as a rich source of customer IC that must be used to gain a deeper understanding of customers. This knowledge helps to identify the most profitable customers, leads to a richer product set, and improves sales opportunities and customer relationships. For example, tailored messages pertaining to new complimentary product launches and special promotional offers can be sent to customers via e-mail, based on knowledge gleaned through their browses and purchases online.

The Internet has become a micro-marketer's essential tool. It is a world where customers express their interests, preferences and propensities with every click of their mouse. Individual consumer interests and likely buying propensities can be recognised, profiled, and then catered to in a highly individualised way. This information has to be captured and converted into valuable customer IC that can be used to guide the customer directly to those products and services that hold the most interest for him/her, and to present them in a manner that encourages a positive conclusion to the transaction (Tanoury 2002: Internet \& Gingrande 2002: Internet).

In order to ensure the capture and conversion of the above-mentioned valuable information, a knowledge conversion team must be assigned to constantly monitor the company's web site and extract useful information. This information can then be codified, converted into knowledge (IC) and stored in the knowledge repository with an accompanying special alert tag for the marketing department. This will ensure that valuable and accurate customer knowledge gets to the right people (the marketing personnel) at the right time so that product-and-service offerings and customer profiles can be adjusted accordingly and timeously for improved competitiveness.

\section{CRM Call Centres}

There are many challenges to maintaining high levels of customer satisfaction. The primary challenge is ensuring that all call centre agents have access to IC on customers to ensure the same consistent level of service and, in so doing, ensure a better relationship with customers (Gartner 2002: Internet).

IC can also allow an organisation to convert call centres from cost centres into profit centres through cross-selling (selling additional unrelated products) and up-selling (selling more expensive variations or more of the same or similar products).

IC that is shared and leveraged provides the following benefits:

- If customer IC is properly captured and shared in a central repository, all call centre agents will have access to vital customer profile and relationship knowledge. This means that all agents have access to the same knowledge and a consistent, informed, and accurate level of service can be given, improving the service delivery process and customer satisfaction. It also doesn't matter if key agents that usually handle specific 
customer queries leave, as the IC on that customer has been shared and subsequent interactions can be handled by another agent.

- Having in-depth knowledge of specific and routine customer queries, an organisation can develop automated self-help options for customers with these queries, allowing agents to deal with more complicated and difficult problems.

- Call centre agents can also determine the reasons for customer complaints, and this again is a valuable source of IC that can be used to improve the organisation's product and service offerings and their accompanying level of customer service.

- Having access to full knowledge of the customer (i.e. their likes, preferences, needs and buying propensities) also has an immediate benefit of enhancing the agents' ability to turn service calls into sales opportunities. Based on the customer's demographics, agents can be prompted to suggest and sell other products and services to the customer over the phone. Customer IC can be used to initiate cross-sell and up-sell opportunities with customers, increasing revenue and making the contact centre a growth and profit centre and not just a cost centre (Moore 2000: Internet).

Ultimately, the capturing, sharing and efficient management of customer IC results in a cost reduction within the contact centre, revenue generation through cross-selling and up-selling, and an increase in overall customer satisfaction and loyalty

\section{Predictive CRM Tools}

Predictive CRM is the discipline of getting to know your customers by performing complex analyses on data about them, and is rapidly changing the way companies make operational and strategic decisions about procurement, production, and marketing and sales of products and services. It is a subset of data mining that enables an organisation to derive new insight or new information from existing information. It allows an organisation to perform activities like: predicting estimated life-time customer profitability - going beyond how much a customer has spent so far to how much an organisation anticipates that customer to spend over his/her life-time; determining which customers are candidates for additional services based on their previous purchasing behaviour and demographics; determining customer churn rates - if a customers shares certain characteristics with those that have left the organisation, they must be offered special promotions to encourage retention; and identifying the most profitable customers and delivering differentiated levels of service to them (Crowder et al. 2001: Internet \& Harney 2003: Internet).

Analytical CRM is therefore a powerful tool where many types of data can be collected and analysed. The results of these analyses is IC that can be used to retain customers and develop better relationships with them through the gaining of a better idea of customer needs and preferences and the better development of customer profiles. IC allows companies to get to know their customers better and to offer them personalised attention, as the knowledge gained can be used to create an in-depth profile of the customer and of their preferences and needs (Haimila 2000: Internet).

In today's economy, there is a great need and demand for data to drive decisions at every level of the company. The most valuable business content in the new economy continues to be about the customer. Knowing everything about their customers not only improves an organisation's existing 
service level, but also opens new revenue opportunities. Using predictive CRM tools and converting the results into valuable IC, means that customer data does not just remain operational with no contribution of value to important strategic decisions that will determine the organisation's success, profitability and competitiveness in the market (Sayan 2001: Internet).

\section{CRM ENABLES THE CAPTURING AND LEVERAGING OF INNOVATIVE CUSTOMER CAPITAL}

"When you think about it, the best source of knowledge to help a company develop its products and markets is its own customers" (Skyrme 2001: Internet).

Organisations need to adopt a value-system approach where customer insights form an integral part of their new research and development efforts. Customers know what they want and their perceptions of competitive products are a valuable source of IC and this capital is integral to the development of new products and services to meet unarticulated needs and unserved markets. Through the capture and leveraging of this IC, a company can unleash new business opportunities (Amidon 2001: Internet).

Progressive companies are realising that a learning partnership (made possible by CRM initiatives) is one of the most viable ways to build long-term relationships with customers and to manage the development of new products and services to fulfill unarticulated customer needs and unserved markets, and in so doing ensure a sustainable competitive advantage. The gathering of customer insight allows for better understanding of new markets, faster time-tomarket for new products, the enhancement of the value of products and services, improved customer service tailored to customers' expressed needs, and higher quality processes. CRM must be employed to ensure happy, satisfied and loyal customers (e.g. analytical tools can be used to track birthdays and anniversaries and special promotions and gifts can be offered accordingly), as satisfied customers will be more than willing to share their innovative capital and participate in new product development processes (Amidon 2001: Internet \& Skyrme 2001: Internet).

Customers are an invaluable source of IC during the new product development process. Their input at each stage ensures that ideas are feasible and properly targeted at real needs and that resources aren't wasted. New product development entails the development of original products, product improvements, product modifications, and new brands through the company's own R\&D efforts.

According to Armstrong \& Kotler (2000: 337-349), new product development follows the following cycle of development:

- Idea Generation - this involves the systematic search for new product ideas through the use of multi-disciplinary, multi-functional teams. Customers must form part of these teams, as they are the best authority on their needs and preferences as well as those of their friends and colleagues.

- Idea Screening - this is the process of screening new product ideas in order to identify good ideas and cancel poor ones as soon as possible. Again customers can inform organisational teams whether the generated ideas will meet their needs and are therefore viable and worth further consideration. 
- Concept Development and Testing - the product concept is a detailed version of the new product idea that is stated in meaningful consumer terms; and concept testing involves the testing of new product concepts with a group of target consumers to discover whether the concepts have strong consumer appeal - consumers are a rich source of IC to ensure concept viability and feasibility.

- Marketing Strategy Development - this involves the design of an initial marketing strategy for a new product based on the product concept. Customer input allows for the better targeting of the marketing mix elements - consumers will express what sales channels and outlets they prefer as well as what price ranges are acceptable to them.

- Business Analysis - this involves a review of the sales, costs and profit projections for a new product in order to discover whether these factors satisfy the company's objectives. Here customers provide no input, except in what prices are acceptable to them, which affects the projected profits.

- Product Development - this entails the development of the product concept into a physical product in order to ensure that the product idea can be turned into a workable product. This process requires intense collaboration between research and development, the various functional areas and customers to ensure the commercial viability of the product.

- Test Marketing and Commercialisation - this involves the testing of the product and marketing program in more realistic market settings and the introduction of the final product into the market. The use of customer IC from the beginning of the new product development process will ensure better success for these phases.

Customers are a valuable source of IC and can be used to ensure the success of new product development as well as to ensure that resources are not wasted. Relationships with customers must be managed and customers must be kept satisfied and loyal in order to ensure their contribution to this process and that they are willing to share their ideas and IC. Better targeted and developed new products that are tailored to customer needs and preferences afford an organisation an edge over competitors and make that organisation more competitive in the market place.

\section{THE STRATEGIC BENEFITS OF CAPTURING AND LEVERAGING CUSTOMER INTELLECTUAL CAPITAL THROUGH CRM INITIATIVES}

There is currently an increasing awareness that the value of customer IC, when applied across a company, builds market insight and expertise within the enterprise. The application of customer IC also enables the specific strategic benefits of maximising marketing productivity, developing better customer contact strategies; and aiding strategic decisions (Acxiom Corporation 2003: Internet).

Each one of these is explored in more detail below.

- Maximising Marketing Productivity 
Customer IC can be used to increase and improve the decision-making process for marketing applications. These applications include activities designed to: acquire the best customers; increase their value to the firm; retain the business of the most valued customers; or recover valued customers lost to competitors. IC can be used to identify target markets, to figure out what products and services to offer each customer segment, to test different pricing strategies, and to manage multiple communication channels, including direct mail, telemarketing and the Web.

Customer acquisition used to rely on mass advertising in print and broadcast media. However, companies can now extract customer information from their various operational systems and consolidate it in a marketing database or warehouse, enhance it with demographic information to create valuable IC, create response models, and use these to sell more to existing customers and to seek new individuals who resemble their best customers.

Customer IC also assists in customer development and retention, which is especially important in businesses where the perceived cost of switching suppliers is low. IC can also be used to increase customer life-time value through cross-selling and up-selling and to retain the best customers and match them with new products.

\section{- Developing Better Customer Contact Strategies}

Customer IC enables the better design and execution of customer-focused contact strategies. In order to be effective, the contact strategies should be segment-specific, multi-dimensional, actionable and measurable. These dimensions involve:

(Nykamp Consulting Group 2003: Internet)

- Segment-specific - mass marketing is no longer profitable and marketing strategies must now be tailored to meet the needs, preferences and interests of multiple customer segments. The organisation must understand the product, service, timing, pricing, channel, and media preferences of their customers within each segment. For this understanding, IC needs to be gathered from customer relationships and leveraged accordingly.

- Multi-dimensional - a customer contact strategy must consider all types of interactions with customers such as advertising, telephone via call centres, the Internet, direct mail, etc. The customer must receive the same consistent message, and the provision of uniform access to captured customer IC will ensure this.

- Actionable - a contact strategy should be clearly documented for each customer segment and must take into consideration that customers will move between segments over time. The strategy will incorporate both contacts directed at the entire segment as well as more individualised contacts triggered by individual behaviors. IC will ensure that there is sufficient knowledge on customer preferences and their behaviours to develop the appropriate and efficient actionable strategies.

- Measurable - an organisation must be capable of measuring the impact of their contact strategy on each customer segment. This can be achieved by gathering 
feedback from customers and this feedback is a valuable source of IC for ongoing improvement.

Companies are able to have more meaningful interactions with customers when they implement a multi-dimensional segment-specific contact strategy. An actionable and measurable strategy will also result in increased customer value, and long-term loyalty. So customer IC is used to develop more effective contact strategies, which in turn result in improved customer relationships where even more transactional and innovative capital can be captured and leveraged.

\section{- $\quad$ Aiding Strategic Decisions}

Customer IC has become a key strategic lever for maximising the profitability of each customer, product, and delivery channel. This capital can be used to aid and enhance strategic decisions such as:

- How to optimise the mix of direct, indirect, and online sales channels.

- What products to offer, in what combinations, and at what price, to particular customer segments?

- How to best allocate advertising resources for maximum media efficiency and impact.

- Minimising risk - as companies become more adept at capturing and leveraging customer IC, they can make better informed strategic decisions and reduce resource wastage on unviable customers and products.

Customer IC also improves product allocation decisions. Not every customer is suited to every product and IC can help an organisation to determine customer propensities to buy certain types of products. This enables an organisation to develop appropriate pricing and merchandising strategies, including:

- What combinations (or bundles) of products to create in order to maximise profitability in important customer segments?

- How to create differentiated pricing strategies that incentivise customers to behave in a desired fashion. For example, can lower value customers be encouraged to do business via lower cost channels by giving them a differentiated product at a lower price?

- Which product lines should be procured and in what depth for each store location to meet the needs of customers in that store's trading area?

Customer IC is an invaluable resource for improving the accuracy, efficiency and viability of strategic decisions. 


\section{CHALLENGES FACING THE IMPLEMENTATION OF CRM}

The primary disadvantages to implementing CRM (and the subsequent capture of IC) lie in its implementation. Deploying a CRM system requires the re-engineering of business processes and an organisation needs to make the deployment and nurturing of profitable customer relationships a priority for all employees (Tanoury 2002: Internet).

The biggest reason why CRM initiatives fail is a lack of user acceptance. Users have to embrace the system in the first place before it can ever be successfully implemented. While it may be sold at the boardroom level, it succeeds or fails at the end-user level. Another hurdle to the effective implementation of a CRM initiative is a lack of data integrity as well as a lack of integration of data sources.

According to Brock (2003: Internet), the following challenges should be considered when implementing CRM:

- CRM not aligned with overall organisational strategy - an organisation should start from the right strategic place, where business goals and processes should be considered before selecting or upgrading CRM solutions. It must be determined how CRM can help the organisation achieve their objectives. Instead of making uninformed and hierarchical decisions in the boardroom, input from the actual users themselves about current sales, marketing and customer service processes must be encouraged.

- Users reluctant to employ CRM - the organisation must create a sense of user ownership. Employees will only be enthusiastic about something they help create and will have a vested interest in the success of an initiative if they play a role in its development. A task force should be formed with users at all organisational levels to help select the best CRM system. Feedback systems must also be implemented that will create a sense of ownership and encourage continuous improvement.

- Lack of support for CRM - the benefits of the CRM initiative must be promoted internally. Users must be courted in the same way that the company would promote its products to a customer. It is human nature to resist change and that is why dealing with potential user objections and concerns must be done from the start. A company's communications team must be used to promote the advantages of CRM during employee meetings, through the company's intranet site, as well as through internal publications.

However, one of the most important implementation challenges to consider is the creation of the correct corporate culture and of addressing employee resistance to change. The CRM initiative needs to be constantly promoted and communicated within the company, and incentives must be provided and friendly competitiveness encouraged, in order to achieve the desired culture change.

\section{CONCLUSION}

It is evident, from the evidence provided in this article, that the implementation and adoption of CRM practices and principles is essential to any organisation wishing to capture and leverage customer IC and, thereby, increase the organisation's competitiveness and profitability. 
Organisations must understand that customers represent two sources of IC: both transactional and innovative capital; as well as how the development and maintenance of good relationships with customers can unlock this capital that can then be leveraged by the organisation to develop better marketing programs, to be more responsive to customer needs, and to reap the other strategic benefits explored in this article to improve the organisation's strategic competitive position.

However, organisations must realise that the issues of developing a customer orientated culture, constantly updating integrated technologies and the other implementation challenges highlighted in the article must be carefully considered before CRM deployment. CRM initiatives require enterprise-wide acceptance and constant maintenance and resource allocation in order to provide the organisation with the valuable customer IC that they need for sustainable competitiveness.

Relationship capital, as explored through SRM and CRM in the first two articles of the intellectual capital management series, is extremely valuable in that it enhances an organisation's ability to gain and leverage a competitive advantage (and often a sustainable competitive advantage) over its competitors. Relationship capital must however be supplemented and enhanced by structural capital in order for the full benefit of sustainability to be realised. Structural capital consists of innovative intangibles such as brands and patents; intangible processes and methodologies; and organisational philosophies, structures and cultures.

\section{CLOSURE}

Much attention has previously been paid to the value-adding benefits of organisational philosophy, culture and structures, and consequently the third article of the series explores the value-adding and creating potential of innovation and process structural capital.

\section{REFERENCES}

AB Office Solutions. 2003. The Advantages of CRM [Online] Available from: http://www.aboffice.com.au/webdesign/default.asp?pid=products\&product=crm [Downloaded: 2003-02-16].

Acxiom Corporation whitepaper. 2003. Transform Customer Knowledge into Strategic Advantage. [Online] Available from: http://www.dmreview.com/master.cfm?NavID=61\&whitepaperID=33 [Downloaded: 2003-02-16].

Amidon DM. 2001. Customer Knowledge is NOT Knowledge of the Customer [Online] Available from: http://www.skyrme.com/updates/u18.htm [Downloaded: 2003-02-16].

Armstrong G \& Kotler P. 2001. Principles of Marketing. $9^{\text {th }}$ ed. New Jersey: Prentice Hall.

Brock R. 2003. A Prescription for the CRM Syndrome. [Online] Available from: http://www.realmarket.com/experts/experts110502.html [Downloaded: 2003-02-17].

Crowder HP. 2001. Predictive Customer Relationship Management: Gaining Insights about Customers in the Electronic Economy [Online] Available from: http://www.dmreview.com/master.cfm?NavID=198\&EdID=3020 [Downloaded: 2003-02-18]. 
Du Plessis PJ, Jooste CJ \& Strydom JW. 2001. Applied strategic Marketing. Johannesburg: Heinemann.

Erb J. 2001. Leaving the Barn Doors Open [Online] Available from: http://www.destinationcrm.com/default.asp?ArticleID=1305\&KeyWords=\%22intellectual+capital\% 22 [Downloaded: 2003-02-18].

Gartner Inc. whitepaper. 2002. Knowledge Management: The Key to Customer Service Success [Online] Available from: http://www.serviceware.com/pdf/whitepaper-key.pdf [Downloaded: 2003-02-16].

Gingrande A. 2002. Relationship Marketing: A Competitive Advantage for B2C [Online] Available from:

http://www.kmworld.com/publications/magazine/index.cfm?action=readarticle\&article_id=1022\&p ublication_id=1 [Downloaded: 2003-02-16].

Haimila S. 2000. Building One-On-One Relationships [Online] Available from: http://www.kmworld.com/publications/magazine/index.cfm?action=readarticle\&article_id=977\&pu blication_id=1 [Downloaded: 2003-02-16].

Harney J. 2003. Predictive Analytics: Forecasting Future Trends from Existing Data [Online] Available from:

http://www.kmworld.com/publications/magazine/index.cfm?action=readarticle\&article_id=1404\&p ublication_id=1 [Downloaded: 2003-02-16].

Henricks M. 2000. More Than a Fling [Online] Available from: http://www.entrepreneur.com/Magazines/MA_SegArticle/0,1539,278637----1-,00.html [Downloaded: 2003-02-18].

Magic Software Enterprises whitepaper. 2000. The CRM Phenomenon [Online] Available from: http://www.dmreview.com/whitepaper/wid259.pdf [Downloaded: 2003-02-16].

Moore A. 2000. Knowing the Customer [Online] Available from:

http://www.kmworld.com/publications/magazine/index.cfm?action=readarticle\&article_id=586\&pu blication_id=1 [Downloaded: 2003-02-16].

Nykamp Consulting Group. 2003. Developing Customer Contact Strategies [Online] Available from: http://www.informationweek.com/story/IWK20030209S0002 [Downloaded: 2003-02-18].

Sayan E. 2001. It Is All About Knowing Your Customer [Online] Available from: http://www.kmworld.com/publications/whitepapers/KM/sayan.pdf [Downloaded: 2003-02-18].

Skyrme D. 2001. Customers - A New Twist on Knowledge Management [Online] Available from: http://www.skyrme.com/updates/u5.htm [Downloaded: 2003-02-18].

Tanoury D. 2002. Missing the Mark: Why Most CRM Plans Fail [Online] Available from: http://www.computerworld.com/news/2002/story/0,11280,67730,00.html [Downloaded: 2003-0216]. 
Tanoury D. 2002. Web-Enabled Customer Relationship Management [Online] Available from: http://www.dmreview.com/whitepaper/WID478.pdf [Downloaded: 2003-02-16]. 